\title{
Improving Learning: Underlying Factors And Suggestions To Improve Learning In Health Profession
}

\author{
Farhat Fatima, Shafaq Sultana
}

\section{INTRODUCTION:}

Learners in health professions education may struggle with learning and educationist can help them to explore what can be followed to optimize it.

A multitude of factors influence the storage and retrieval of information stored in memory. These include, but are not limited to the implications and understanding gained out of that piece of information, how it is learned, the contextual conditions during its learning and if relevant practices are employed during its retrieval. ${ }^{1}$

\section{Rationale:}

To organize processed information; building blocks of cognition are linked in large networks. This idea of network is very useful for thinking about how information is stored in and retrieved from memory. Cognitive units in these networks act as nodes and there are links between them that represent their relationship. During recall, activation of the stimulated node (nodal activation) spreads along the links to the nodes directly connected with the concept and to nodes linked with these nodes and so on (spreading activation). Students can have problems in comprehending information and using it effectively in cognitive operations if they are unable to create quality networks for building blocks of cognition. ${ }^{2}$ Thus efficient recall depends on our understanding of what information means and being able to find it. $^{2}$

\section{Underlying factors:}

Students can have problems with recall if:

- $\quad$ They do not actively condense and organize material into meaningful chunks to overcome the constraints of limited processing capacity posed by working memory. The human mind can become cognitively overloaded if more than seven pieces of information are simultaneously presented to working memory for processing. This may lead to inefficient attempts at thinking and problem solving leading to limited learning. ${ }^{1,3-7}$

Farhat Fatima
Clinical Tutor, Clinical Academic Sciences
College of Medicine, Qatar University
Shafaq Sultana
Senior Lecturer, Department of Medical Education
Bahria University Medical and Dental College
Email: dr.shafaqsultana@gmail.com
Received: 27-02-2019
Accepted: 23-04-2019

- Students cannot achieve meaningful learning and therefore may have problems with recall later if they are not actively involved in selecting, organizing and integrating the currently presented information with prior relevant knowledge activated from long-term memory and brought into working memory for processing. $1,2,4,7$

- How a student encodes to-be-remembered information makes a huge difference in how well she recollects it. ${ }^{1,8}$ Student can have problems with recall if they do not take active participation in the encoding process by constructing meaning and using variety of approaches to organize, enrich and add new information. This means they are not employing elaborative rehearsal. ${ }^{1,2,6,8}$ Research suggests that elaborative rehearsal (Referring to deeper and diverse activities while encoding) is superior to maintenance rehearsal (refers to surface encoding) for long term recall. ${ }^{8}$

- Problems with learning can also occur if the educational strategies are not focused at enhancing meaning, reducing contextual reliance, and providing recurrent, relevant practices at recovering information. At the time of retrieval memory could be efficiently searched when conditions and cues at retrieval match those present at encoding, a phenomenon known as encoding specificity. ${ }^{1,9}$

- $\quad$ Retaining knowledge and skills seems to be in direct relationship to the frequency with which they are used. Thus, engaging in massed practice rather than distributed practice can lead to problems in long-term knowledge retention. Massed practice exhausts the cognitive resources, thereby increasing cognitive load and eventually ensuing minimal learning. $5,9,10$

- Lack of a broad knowledge base, automaticity, sufficient strategies for learning, and metacognitive knowledge about when, where and why to use them combined with an inability to ignore distractions can all lead to inefficient encoding and problems with learning. ${ }^{1,8}$

In 2013, the monograph was published by DunloskyJ, et al, on improving students learning with effective learning techniques. Following were the techniques discussed in the monograph followed by suggestion based on their utility. Elaborative interrogation, Self-explanation, Summarization, Highlighting/underlining, Keyword mnemonic, Images, Rereading, Practice testing, Distributed practice and interleaved practice. To explore the best technique, the utility of each techniques were evaluated based on four parameters: 
learning conditions, student characteristics material used and criterion task. The highest utility in terms of improvement in student learning was found in practice testing and distributed practice and exhibit improved performance of learners in many criterion tasks followed by elaborative interrogation and self-explanation. ${ }^{13}$

\section{Recommendations for improvement:}

- Students can be suggested to use practice testing. During practice testing the learner searches long-term memory in order to redeem the targeted information area. This searching process activates other relevant bits of information as well. All this information can then be encoded collectively in the form of an elaborated trace, facilitating future access to information through assorted routes. ${ }^{13,21}$

- Distributed practice can also help them improve learning by increasing contextual variability ${ }^{9-11,13}$

- Students can improve their learning by employing elaborative interrogation. Deep learning is enforced by raising questions, focusing on knowing how, looking for interrelations and origins, generating hypothesis, constructing multifaceted mechanisms, providing explanations and validations and engaging in evidence based decision making. ${ }^{8,11,13}$

- Learners should try to acquaint themselves with a wide array of encoding strategies along with the metacognitive knowledge to rightly employ them. A premeditated yet flexible approach wherein the employed strategy is best matched with the to be learned content, learning outcomes and assessment type goes a long way. Sometimes it might mean using maintenance rehearsal, but mostly it means deep processing i.e. elaborative rehearsal. ${ }^{8}$

- Constructing knowledge learnt from various sources using own sentences and writing structures and presenting their knowledge in a meaningful way by constructing mechanisms and concept maps can also serve as a valuable tool in improving learning. ${ }^{11,12}$ The same holds true for summarization technique which augments learning by digging out the advanced meaning and essence of the to be learned material. ${ }^{13}$

- Using analogies can help learners by identifying relationships between the familiar model and the new information they are trying to learning. A well-established relationship will help them comprehend the function and structure of the new system they are studying. This allows learners to better understand the different components of a difficult concept, apply it to different real life situations and problem solve with confidence. . $^{11,14,15}$

- Joining a peer-tutoring group can be of benefit in multiple ways like: discovering gaps/inadequacies in knowledge, identifying misconcepts and correct them, enhancing motivation to learning, using time effectively, learning new skills, enhancing collaborative learning and communication and interpersonal skills. ${ }^{11,16,17}$

- Instilling critical thinking skills can help students improve learning by developing self-regulation, analysis and interpretation skills and can also enhance their skills in cognitive and affective dispositions. ${ }^{11,18}$

- They can use rereading as a technique, which improves learning by simply augmenting the bulk of information that gets encrypted.${ }^{13}$ Reflection and self-directed learning have been emphasized as important in the process of learning. By assessing their own progress and critically analyzing achievements, students can become a life-long, self-regulated learner. ${ }^{11,19,21}$

- Using a wide range of learning resources and suiting them to the stage and purpose, can help students get the best out of each learning resource and build links between resources and learning needs. ${ }^{11}$

- Application of learnt knowledge to new problems can help students assimilate knowledge from varied topics/areas of study, explore associations between concepts, practice a number of cognitive skills as ell as determine any shortfalls or breaches in their comprehension. ${ }^{11}$

- Interleaved practice (learning by mixing up topics or subjects) has been shown to improve learning by providing learners with an opportunity for comparison between varying concepts and problems. It also helps because of the distributed retrieval from long term memory. ${ }^{13}$

- Students should ask for regular feedback to improve learning and accept it because unless feedback is accepted by the recipient it cannot be effective. ${ }^{11,22}$

\section{CONCLUSION:}

The comprehensive overview and an awareness of the possible underlying factors associated with effortful learning, along with a repertoire of strategies to improve can be of help to both faculty, and students in health professions, as this provides them with a handy resource to refer to when experiencing learning issues.

\section{REFERENCES:}

1. Regehr G, Norman GR. Issues in cognitive psychology: Implications for professional education. Acad Med 1996;71(9):988-1001.

2. Bruning RH, Schraw GJ, Norby MM. Long-term memory: structures and models. In: Cognitive psychology and instruction. $5^{\text {th }}$ ed. Boston: Pearson education Inc;2011:p. 3764.

3. Miller GA. The magical number seven plus or minus two: Some limits on our capacity for processing information. Psychol Rev 1956;63:81-97. 
4. Bruning RH, Schraw GJ, Norby MM. Sensory, short-term and working memory. In: Cognitive psychology and instruction. $5^{\text {th }}$ ed. Boston: Pearson education Inc;2011:p. 1336

5. Raman M, McLaughlin K, Violato C, Rostom A, Allard JP, Coderre $\mathrm{S}$. Teaching in small portions dispersed over time enhances long term knowledge retention. Med Teach 2010;32:250-255.

6. Ruiter DJ, Van Kesteren MT, Fernandez G. How to achieve synergy between medical education and cognitive neuroscience? An exercise on prior knowledge in understanding. Adv in Health Sci Educ 2012;17:225-240.

7. Mayer RE. Applying the science of learning to medical education. Med Educ 2010;44:543-549.

8. Bruning RH, Schraw GJ, Norby MM. Encoding processes. In: Cognitive psychology and instruction. $5^{\text {th }}$ ed. Boston: Pearson education Inc;2011:p. 65-89.

9. Bruning RH, Schraw GJ, Norby MM. Retrieval processes. In: Cognitive psychology and instruction. 5th ed. Boston: Pearson education Inc;2011:p. 90-106.

10. Kerfoot BP, DeWolf WC, Masser BA, Church PA, Federman DD. Spaced education improves the retention of clinical knowledge by medical students: Randomized controlled trial. Med Educ 2007;41(1):23-31.

11. Azer SA, Guerrero APS, Walsh A. Enhancing learning approaches: Practical tips for students and teachers. Med Teach 2013;35:433-443.

12. Pinto AJ, Zeitz HJ. Concept mapping: a strategy for promoting meaningful learning in medical education. Med Teach 1997;19:114-121.
13. Dunlosky J, Rawson KA, Marsh EJ, Nathan MJ, Willingham DT. Improving student's learning with effective learning techniques: Promising directions from cognitive and educational psychology. Psychol Sci Public Interest 2013;14(1):4-58.

14. Sircar SS, Tandon OP. Teaching nerve conduction to undergraduate: The travelling flame analogy revisited. Adv Physiol Educ 1996;15(1): S78-S80.

15. Busari JO. Revisiting analogy as an educational tool-PBL and the game of basket ball. Med Educ 2000;34:1029-1031.

16. Hill E, Liuzzi F, Giles J. Peer-assisted learning from three perspectives: student, tutor and co-ordinator. Clin Teach 2010;7(4):244-246.

17. Cate OT, Durning S. Peer teaching in medical education: Twelve reasons to move from theory to practice. Med Teach 2007;29:591-599.

18. Simpson E, Courtney M. Critical thinking in nursing education: A literature review. Intl J Nurs Pract 2002;8:89-98.

19. Tagawa $M$, Imanaka $H$. Reflection and self-directed and group learning improve OSCE scores. Clin Teach 2010;7(4):266270.

20. Sandars J. The use of reflection in medical education: AMEE Guide No. 44. Med Teach 2009;31:685-695.

21. Larsen DP, Butler AC, Roediger HL. Repeated testing improves long-term retention relative to repeated study: A randomized controlled trial. Med Educ 2009;43(12):1174-1181.

22. Milan FB, Dyche L, Fletcher J. How am I doing? Teaching medical students to elicit feedback during their clerkship. Med Teach 2011;33:904-910. 